\title{
Effect of Resin Infiltration on Bleached Enamel: An In Vitro Evaluation of Micromorphology, Resin Penetration and Microhardness
}

\section{Zhen Wei}

Stomatology Hospital of Guangzhou Medical University

Yanhui Lu

Stomatology Hospital of Guangzhou Medical University

Weidong Wang

Stomatology Hospital of Guangzhou Medical University

Jiawen Gan

Guangzhou Medical University

xuechao Yang ( $\nabla$ Xyang.gmu@gmail.com )

Stomatology Hospital of Guangzhou Medical University, Key Laboratory of Oral Medicine, Guangzhou Institute of Oral Disease

Research article

Keywords: tooth bleaching, resin infiltration, micromorphology, penetration depth, microhardness

Posted Date: December 10th, 2020

DOI: https://doi.org/10.21203/rs.3.rs-122642/v1

License: (c) (1) This work is licensed under a Creative Commons Attribution 4.0 International License.

Read Full License 


\section{Abstract}

Background: Tooth bleaching is a promising aesthetic treatment for shaded teeth; however, demineralized lesions also occur after bleaching, and Icon resin can infiltrate into the demineralized lesions and then improve the color of teeth. This study aims to evaluate the effectiveness of resin infiltration on bleached teeth that are managed with different protocols by assessing the micromorphology of enamel surfaces, the depth of resin penetration and the microhardness of enamel after bleaching and Icon resin infiltration.

Methods: A total of 150 noncarious premolars with sound coronal structure, which were extracted for orthodontic purposes, were obtained in this study in three parts: part $\nabla^{\prime \prime m i c r o m o r p h o l o g y ~ o f ~ e n a m e l ~}$

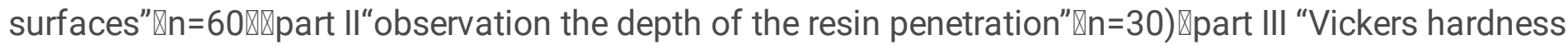
number values" $₫ n=60)$. Both part $\otimes$ and part III were divided into six subgroups. Part II was divided into three subgroups. 10 samples per subgroup. Data were analyzed using SPSS 22.0, Mann-Whitney test.

Results: The surface roughness of the teeth increased after bleaching. When etched with $15 \% \mathrm{HCl}$ before the resin infiltration, it would result in further increase in roughness, but the surface of the bleached teeth could be as smooth as that of normal teeth after resin infiltration. There was a statistically significant increase in the mean resin penetration depth of the bleached teeth with 5-day delay of resin infiltration over the bleached teeth with resin infiltration immediately (Mann-Whitney test, $P<0.05$ ). Otherwise邓the $\mathrm{VHN}$ values of delayed ones were similar to the normal one.

Conclusions: It suggested that Icon resin infiltration treatment should be delayed after tooth bleaching but not performed right after tooth bleaching.

\section{Background}

Tooth bleaching is an aesthetic way to change the color of teeth without cutting hard tissue, and its success is directly related to the diffusion capacity of hydrogen peroxide $(\mathrm{HP})^{1}$ ). After the bleaching gel is applied on the tooth surface, the $\mathrm{pH}$ then becomes acidic, achieving the effectiveness of the gel whitening function but in the meantime possibly damaging the tooth structure ${ }^{2-4)}$. Extensive literatures ${ }^{5-9}$ ) have reported that the surface of teeth often show decreased enamel hardness and mineral loss after bleaching. Many studies have also found that after a certain degree of demineralization appeares in the enamel, dissolution and surface roughness increased after the application of bleaching material, causing micromorphology alterations ${ }^{10-12)}$. When the concentration of the bleaching reagent increases and the bleaching time increases, the dissolution of enamel intensifies, becoming similar to fish scales. Additionally, the interspace ratio of teeth also increases ${ }^{13)}$.

In addition to tooth bleaching, resin infiltration (RI) can also improve the color of teeth. In recent years, as a much more tissue-preserving approach, RI is developed to improve the color of teeth when applied to rest and control white spot lesion, shallow caries lesion, dental fluorosis and demineralization. For this treatment, a new resin, Icon®-DMG Germany has a lower viscosity and is mainly composed of bisphenol 
A glycidyl methacrylate, triglyceride dimethacrylate and ethanol. After etching the enamel surface of shallow caries with $15 \%$ hydrochloric acid $(15 \% \mathrm{HCl})$, some white spots can be removed and fully expose surface micropores. Then the Icon resin could penetrate into the pores and fill in the hard tooth tissue lost, and preventing the entry of acid and ending caries ${ }^{14}$ ). Normal tooth enamel is translucent, with a refractive index of 1.62; the refractive index of Icon resin is $1.475^{15}$ ). After the Icon resin infiltrates into the demineralized enamel and solidifies, the overall refractive index of the enamel is close to that of normal enamel, with the chalky appearance and color of the enamel having been greatly improved. Since the refractive index of Icon resin is close to that of natural tooth enamel, it has been gradually used combined with tooth bleaching in the therapy of shaded teeth. Wang et al. suggested that it seemed to be a minimally invasive therapy for severe dental fluorosis by combining the tooth bleaching and resin infiltration to achieve the esthetic appearance ${ }^{16)}$.

With the knowledge that both $\mathrm{HP}$ applying in bleaching technique and $15 \% \mathrm{HCl}$ using in $\mathrm{RI}$ causing certain amounts of acid erosion and subsequently resulting in demineralization, will the performance of Icon resin infiltration right after tooth bleaching cause excessive etching and do harm to the restorative function of Icon resin? Otherwise, Lai et al. ${ }^{17)}$ reported that the decomposition of oxygen in HP diffusing in enamel, inhibits the polymerization of resin. It led to the decrease in the resin bonding tensile strength after bleaching and it was indicated that it may need to be delayed for at least 7 days to make sure the enamel adhesion ability recover ${ }^{18)}$, while data from Bargih et al. ${ }^{19-20}$ ) have shown that the use of ethanol-based adhesives might reverse the drop in bond strength found immediately after bleaching, in which the ethanol accounted for. For Icon resin is a new kind of resin material with excellent fluidity that could achieve the penetration into the demineralized lesions and stabilize the tooth color. Will the decomposition of oxygen in HP diffusing in enamel inhibit the penetration depth of Icon resin, too? At present, there is still a lack of studies concerning the effect of immediate infiltration on the restorative function of Icon, and the questions warrant extensive research to formulate evidence-based guidelines for their combined application.

In conclusion, the aim of this in vitro study was to evaluate the effectiveness of resin infiltration on bleached teeth with or without $15 \% \mathrm{HCl}$ and researching whether the delay of $\mathrm{RI}$ is necessary or not. The study assessed the depth of resin penetration into bleached enamel, the microhardness and the micromorphology of post-infiltration to determine whether a better effect could be achieved with a delay of $\mathrm{RI}$ and etching with $15 \% \mathrm{HCl}$ after bleaching.

\section{Materials And Groups}

\section{Preparation and groups of specimens}

A total of 150 noncarious premolars with sound coronal structure, which were extracted for orthodontic purposes, were obtained. These teeth were stored below room temperature in distilled water until they were subjected to any intervention. This present experiment consisted of 3 parts. 
Part I: Evaluating the micromorphology of enamel surfaces. In this part, 60 samples were divided into 6 subgroups and 10 samples for each subgroup: la: control group;lb:10 samples were subjected to a bleaching agent with $40 \%$ hydrogen peroxide (HP);lc:10 samples were subjected to a bleaching agent with $40 \% \mathrm{HP}$ and immediately etched with $15 \%$ hydrochloric acid $(15 \% \mathrm{HCl})$; Id: 10 samples were bleached with $40 \% \mathrm{HP}$ and infiltrated with Icon®-DMG Germany; le:10 samples were subjected to a bleaching agent with $40 \% \mathrm{HP}$ and immediately etched with $15 \% \mathrm{HCl}$, and then infiltrated with Icon®-DMG Germany; If (10 samples)were placed in artificial saliva for 5 days after being bleached with $40 \% \mathrm{HP}$ and etched with $15 \%$ $\mathrm{HCl}$, after which were infiltrated with Icon ${ }^{\circledR}-\mathrm{DMG}$ Germany.

Part II: Evaluating the depth of resin penetration tags. In this part, 30 samples were divided into 3 subgroups and 10 samples for each subgroup: Ila - bleached and infiltrated with Icon®-DMG Germany; $\mathrm{Ilb}$ - post-Icon resin infiltration after being bleached and etched with $15 \% \mathrm{HCl}$; Ilc- post-Icon resin infiltration after being bleached and etched with $15 \% \mathrm{HCl}$ as well as a placing in artificial saliva for 5 days. The depth of resin penetration and the micromorphology of the surface were studied using scanning electron microscopy (SEM).

Part III: Evaluating Vickers hardness number (VHN) values of enamel. In this part, other 60 teeth were equally divided into six subgroups (10 samples/subgroup) as group I and VHNvalues were obtained to measure the surface microhardness.

Table 1

Protocols in Part I\& Part III

\begin{tabular}{|lll|}
\hline I & Protocols & Samples (n) \\
\hline a & Control group & 10 \\
b & Bleaching & 10 \\
\hline c & Bleaching + 15\% HCl & 10 \\
\hline d & Bleaching + immediate RI & 10 \\
\hline e & Bleaching + 15\% HCl + immediate RI & 10 \\
\hline f & Bleaching $+15 \% \mathrm{HCl}+$ delayed RI & 10 \\
\hline
\end{tabular}

Table 2

Protocols in Part II

\begin{tabular}{|lll|}
\hline I & Protocols & Samples (n) \\
\hline a & Bleaching + immediate RI & 10 \\
b & Bleaching $+15 \% \mathrm{HCl}+$ immediate RI & 10 \\
\hline c & Bleaching $+15 \% \mathrm{HCl}+$ delayed RI & 10 \\
\hline
\end{tabular}




\section{Methods And Procedure}

After allocation, the specimens were treated respectively. Before the bleaching procedure, specimens were gently dried with air for moisture control. For I (b, c, d, e, f), II (a, b, c) \& III (b, c, d, e, f), the 40\% HP were applied evenly on the enamel surface for office bleaching, obtaining a uniform gel layer of 2-mm thickness for 20 minutes and then repeated once more. After bleaching. I(c,e), II b,and $\otimes(c, e)$ were etched with $15 \% \mathrm{HCl}$ for 2 minutes. After each application time, all specimens were abundantly rinsed with distilled water for 30 seconds until the products were completely removed, and were air-dried. In the last session of each protocol, the specimens ( Id, le, II a,II b \& $\nabla d$, $\nabla$ e ) were submitted to application of Icon $®$ DMG Germany for 3 minutes immediately after etching and then the samples above were maintained in distilled water at $37^{\circ} \mathrm{C}$ for the duration of the entire experiment. If, IIc and IIIf were placed in artificial saliva at $37^{\circ} \mathrm{C}$ for 5 days before etching and RI. The resin was applied as follows: a solution of $99 \%$ ethanol was applied for 30 seconds, and the specimen was air-dried followed by Icon resin infiltration application, which was left on the enamel for 3 minutes before curing. The resin was light-cured for 40 seconds. The application of resin was repeated for 1 minute and again light-cured for 40 seconds. 90 samples from the total were randomly selected for SEM analysis (I \& II), and a sample size of 60 was selected for the microhardness test ( III).

\section{Scanning Electron Microscopy}

Samples from I were sectioned in the mesial-distal plane. Samples from II were sectioned in the buccolingual plane using a hard tissue microtome (Leica 1600). All the blocks were then subjected to a drying process by placing them in a hot air oven (Heathron Industrial Heaters) for 10 minutes at $110{ }^{\circ} \mathrm{C}$. Samples were then ready to be subjected to SEM (JEOL, JSM-6380LA) to investigate the micromorphology of the enamel surface and the depth of penetration of the infiltrant.

\section{Surface Microhardness Evaluation}

A Vickers microhardness tester (CLEMEX CMT HD) was used to investigate the change in hardness after bleaching and Icon resin infiltration. Teeth in III were tested for enamel microhardness. For the microhardness testing, a load of $100 \mathrm{gm}$ was applied for 10 seconds as recommended. Three indentations were performed on the enamel surface, and the microhardness even values were recorded.

\section{Statistical Analysis}

The data were statistically processed using SPSS 22.0 software. A Mann-Whitney test was performed for the comparison of values between two subgroups. $P<0.05$ indicated that the difference was highly significant. 


\section{Results}

SEM revealed the roughness of the bleached enamel increased in $\mathrm{lb}$, compared with which, the roughness of the bleached enamel etched with $15 \% \mathrm{HCl}$ in Ic was obviously increased at $50 \times$ magnification(Fig. 1 ).

Upon comparing the microsurfaces among la-f, it was determined that the microsurface after Icon resin infiltration (Id, le and If) could be as smooth as that of normal teeth (la) at $50 \times$ magnification (Fig. 2).

The SEM observation of resin infiltration samples showed resin-infiltrated tags. Inlla, the deepest depths of infiltration were determined to range from 245 to $317 \mu \mathrm{m}$, and the mean depth was $284 \mu \mathrm{m}$ (Table 3 ). Figure 3 shows the depth of resin penetration in one sample fromlla at two different magnifications of $250 \times$ and $500 \times$.

Table 3

Depth of penetration of resin tags in Ila

\begin{tabular}{|ll|}
\hline Sample no. & Penetration depth \\
\hline 1 & 245 \\
2 & 300 \\
\hline 3 & 268 \\
\hline 4 & 290 \\
\hline 5 & 317 \\
\hline 6 & 254 \\
\hline 7 & 266 \\
\hline 8 & 305 \\
\hline 9 & 289 \\
\hline 10 & 315 \\
\hline mean & 284 \\
\hline
\end{tabular}


Table 4

Depth of penetration of resin tags in IIb

\begin{tabular}{|l|l|}
\hline Sample no. & Penetration depth $(\mu \mathrm{m})$ \\
\hline 1 & 397 \\
\hline 2 & 391 \\
\hline 3 & 430 \\
\hline 4 & 422 \\
\hline 5 & 540 \\
\hline 6 & 507 \\
\hline 7 & 534 \\
\hline 8 & 395 \\
\hline 9 & 402 \\
\hline 10 & 417 \\
\hline mean & 443 \\
\hline $\begin{array}{l}\text { Figure 4 showed the depths of resin infiltration in one sample fromllb at two different magnifications } \\
\text { of 250 } \times \text { and 500x. }\end{array}$ \\
\hline
\end{tabular}

Otherwise, the deepest depths of resin infiltration in Ilc ranged from 256 to $402 \mu \mathrm{m}$, and the mean depth of resin infiltration was $371 \mu \mathrm{m}$ (Table 5). 
Table 5

Depth of penetration of resin tags in Ilc

\begin{tabular}{|ll|}
\hline Sample no. & Penetration depth $(\mu \mathrm{m})$ \\
\hline 1 & 400 \\
\hline 2 & 370 \\
\hline 3 & 256 \\
\hline 4 & 385 \\
\hline 5 & 374 \\
\hline 6 & 423 \\
\hline 7 & 368 \\
\hline 8 & 402 \\
\hline 9 & 379 \\
\hline 10 & 356 \\
\hline mean & 371 \\
\hline
\end{tabular}

Figure 5 showed the depths of resin infiltration in one sample from llc at two different magnifications of $250 \times$ and $500 x$.

In total, the mean depths of penetration were $284 \mu \mathrm{min} \mathrm{Ila}, 443 \mu \mathrm{m}$ in Ilb and $371 \mu \mathrm{m}$ in Ilc. There was a statistically significant increase in Ilc over Ila and Ilb in the depth of resin penetration (Mann-whitney test, $P<0.05$ ) (Table 6).

Table 6

Mean depths of resin infiltration of Ila-c

\begin{tabular}{|lr|}
\hline Groups & Mean \pm SD \\
\hline Ila & $284 \pm 6.3 \quad p \otimes 0.05$ (comparing Ila and Ilb, Ilb and Ilc, lla and IIc)HS \\
\hline Ill & $443 \pm 14.2$ \\
\hline Ilc & $371 \pm 14.7$ \\
\hline HS: Highly significant; SD: Standard deviation \\
\hline
\end{tabular}

A Vickers microhardness tester was used to measure the change in hardness of the bleached enamel and enamel post- Icon resin infiltration. Table 7showed the VHN values for III, and Table 6 presents the mean values of microhardness for each subgroup and the intergroup comparisons. Intergroup comparisons were performed between IIId and IIIe, IIIa and IIle, IIla and IIId, IIIb and IIId, IIId and IIIf, IIle and IIIf, using Mann-Whitney test. Compared with the IIla, the VHN values of IIIb-f were low (Mann-Whitney test, $P<$ 
0.05). Otherwise the VHN values of IIIb were higher than IIIc and there was statistically significant between them (Mann-Whitney test, $P<0.05$ ). There was a statistically significant VHN values increase of the teeth with a 5-day delay of RI than that of other groups except the control group. (Mann-Whitney test, $P<0.05)$. In particular, the VHN values of the bleached and etched teeth with a 5-day delay of RI in III were similar to the normal one, which was not statistically significant (Mann-Whitney test, $P \otimes 0.05$ ).

Table 7

VHN values of each sample of each subgroup(III)

\begin{tabular}{|lllllll|}
\hline Sample no. & IIla & IIIb & Illc & IIId & Ille & Illf \\
\hline 1 & 364 & 354 & 313 & 354 & 344 & 355 \\
\hline 2 & 358 & 340 & 314 & 350 & 349 & 360 \\
\hline 3 & 361 & 345 & 317 & 348 & 355 & 358 \\
\hline 4 & 367 & 345 & 317 & 352 & 350 & 364 \\
\hline 5 & 365 & 338 & 316 & 356 & 351 & 353 \\
\hline 6 & 366 & 337 & 312 & 357 & 352 & 365 \\
\hline 7 & 362 & 347 & 309 & 358 & 350 & 364 \\
\hline 9 & 354 & 330 & 313 & 356 & 356 & 355 \\
\hline 10 & 353 & 339 & 314 & 355 & 349 & 361 \\
\hline
\end{tabular}

Table 8

Mean of VHN values of Illa-f

\begin{tabular}{|c|c|c|}
\hline Groups & Mean \pm SD & \\
\hline Illa & $361 \pm 1.2$ & $p \otimes 0.01$ (comparing IIIb and IIIc, IIla and IIle, IIle and IIIf ) HS \\
\hline Illb & $340 \pm 6.4$ & $p \otimes 0.05$ (comparing IIIa and IIId, ,IId and IIIeIIIId and IIIf)HS \\
\hline Illc & $315 \pm 2.4$ & $p \otimes 0.05$ (comparing IIIa and IIIf) \\
\hline Illd & $355 \pm 3.4$ & \\
\hline Ille & $350 \pm 3.5$ & \\
\hline Illf & $360 \pm 4.3$ & \\
\hline
\end{tabular}

Thus, these results indicated that a 5-day delay of RI after tooth bleaching by placing in artificial saliva did significantly affect the surface microhardness of the bleached teeth. If perform the RI immediately, the VHN of the non-etched ones was higher. Though the resin penetration depth of the teeth whose resin 
infiltration was applied immediately after bleaching and etched with $15 \% \mathrm{HCl}$ were highest, they were at the cost of the worse enamel damage before RI (Fig. 1B).In conclusion, based on this experiment, it was indicated that Icon resin infiltration treatment should be delayed after tooth bleaching but not performed right after tooth bleaching generally. If the patients required to do the resin infiltration treatment after tooth bleaching immediately, it was suggested to infiltrate without $15 \% \mathrm{HCl}$ etching.

\section{Discussion}

The RI technique is a new technique used to prevent the development of caries, which can treat early caries without drilling or sacrificing healthy tooth structure around caries ${ }^{21)}$. And now is demonstrated that restoring demineralization, dissolution and abrasion on enamel by resin infiltration is a promising approach for the aesthetic treatment of post-bleaching teeth. It confirms the results obtained in this study. The infiltrant resin used for restoration possesses very low viscosity, high surface tension, and low contact angle with the enamel, all of which are vital properties for penetration of the resin into the body of the enamel.

As is known to all, micropores could occur in the surfaces of enamel after tooth bleaching, which are visible by SEM. The relatively intact enamel surface is slightly damaged. There are many tiny pores that provide the channels for organic acid and minerals diffusing and moving, which can promote bacterial adhesion. After applied with $\mathrm{Rl}$, the color of the demineralization area can be similar to the normal teeth because the refractive index of Icon resin is 1.475 , close to the refractive index of enamel (1.62). RI uses low-viscosity resin to penetrate, plug, and fill the micropores of the demineralization to form a barrier and avoid disintegration of the enamel ${ }^{22}$ ). The present experiment found that the Icon resin penetrated into the demineralization area through SEM observation. The resin penetration depth of etched teeth was deeper than that of the bleached ones without etching (Mann-Whitney test, $P<0.05$ ). The result of deeper penetration may due to the acid. The acid etching technique can punch holes in the enamel surface and can completely remove the surface layer and fully expose the demineralization area ${ }^{23)}$, which can make the resin penetrate into the micropores as deep as possible. While for the VHN value, though the penetration depth increased, the VHN value of the etched ones was less than the bleached ones without etching at the same time(Mann-Whitney test, $P<0.05)$. Moreover, we also found that Icon resin sometimes only penetrated to a certain depth, while some micropores still existed deep in the enamel. Based on our SEM result, etching with $15 \% \mathrm{HCl}$ might cause excessive erosion. Though the resin penetration depth of the bleached teeth with etching were highest, it came at the cost of worse damage of micromorphology after etching. Tamer et al. created the artificial initial caries lesion with an average depth of $200 \mu \mathrm{m}$ and it showed that the Icon penetration depth in the lesion was about $70 \%, 140 \mu \mathrm{m}$ which was deep enough to prevent the further demineralization ${ }^{24)}$. However, there was still some demineralization deep in the enamel due to the $15 \% \mathrm{HCl}$ erosion. Whether deep demineralization can further affect the long-term function of bleached teeth is still unclear and needs further studies. Another reason we took into account was the saliva. The constant presence of saliva and fluoride may minimize changes in the enamel through the deposition of calcium fluoride crystals, mitigating the effects of 
demineralization, prolonging tooth health, and preventing changes that may damage the structure of bleached teeth ${ }^{25}$ ). Furthermore, extensive studies indicated that the bond strength of bleached teeth with a delay of resin bonding were higher than that of the bleached teeth bonded immediately, which had been attributed to the decomposition of oxygen free radicals accountable for the whitening effect in HP diffusing in enamel and adversely influencing the penetration of the bonding agent into the tooth surface and then inhibiting the polymerization of resin 26,27$)$.

Current study used artificial saliva for the experiment. The results showed that with a 5-day delay of RI by placing in artificial saliva for 5 days, the VHN values of the bleached teeth could regain closed to the normal one and better than the other groups(Mann-Whitney test, $P \otimes 0.05)$. Additionally, the penetration depths of the delayed ones were deeper than the bleached teeth which were resin infiltrated immediately $\square$ Mann-Whitney test, $P \otimes 0.05 \square$. Based on the results, we inferred that several elements might account for the result. First, excessive erosion with $15 \% \mathrm{HCl}$ leading the demineralization caused the VHN values decrease. Secondly, decomposition of oxygen free radicals inhibited the polymerization of resin which decreased the bonding strength. As for the delayed ones, it could be attributed to the partial loss of oxygen diffusion layer over time at the tooth and composite interface ${ }^{28)}$ and the constant presence of saliva mitigating the effects of demineralization would account for it. Thus, it is suggested to delay the Icon resin infiltration treatment after tooth bleaching. However, many clinical doctors choose to perform the resin bonding after tooth bleaching immediately. Because both tooth bleaching and RI containing erosion, the immediate combination of these two techniques may cause excessive erosion, decreasing VHN value and polymerization. Barghi et al. ${ }^{19,20}$ indicated that ethanol could eliminate the oxygen free radicals. Thus it is suggested that if the patients required to perform the Icon resin infiltration after tooth bleaching immediately, $15 \% \mathrm{HCl}$ etching was not needed.

In addition, all resins, including the Icon $§-D M G$ Germany, have a disadvantage: aging. Furthermore, clinical long-term follow-up is lacking. Therefore, further studies of the combined application of tooth bleaching and Icon resin infiltration should be performed including long-term follow-ups to study the effects.

\section{Declarations}

\section{Ethics approval and consent to participate}

The present study was approved by the Ethics Committee of the Hospital of Stomatology, Guangzhou Medical University (KY-2017-012). Consent was obtained from all participants and informed consent was signed.

\section{Consent for publish}

Not applicable.

\section{Availability of data and materials}


The datasets used and/or analysed during the current study available from

the corresponding author on reasonable request.

\section{Competing interests}

The authors declare that they have no competing interests.

\section{Funding}

This work was supported by the Health Science and Technology Program of Guangzhou (No.

20191A010068), the Education Science Program of Guangzhou Medical University $₫$ No. 20180119ه冈 the Innovation and Entrepreneurship Training Program for College Students of Guangdong (No.

S201910570039) and the Postgraduate Demonstration Course construction Project of Guangdong Province $₫$ No. 2018SFKC34】.

\section{Authors'contributions}

WZ contributed to the conception and design of the work. GJW contributed

to the acquisition and analysis of data. LYH drafted the Manuscript. WWD and YXC revised the manuscript substantively. All authors read and approved the final manuscript.

\section{Acknowledgements}

Not Applicable.

\section{References}

1. Kimyai S, Bahari M, Naser-Alavi F, Behboodi S. Effect of two different tooth bleaching techniques on microhardness of giomer. J Clin Exp Dent. 2017;9:e249-53.

2. Alqahtani MQ. Tooth-bleaching procedures and their controversial effects: A literature review. Saudi Dent J. 2014;26:33-46.

3. Soares AF, Bombonatti JF, Alencar MS, Consolmagno EC, Honório HM, Mondelli RF. Influence of pH, bleaching agents, and acid etching on surface wear of bovine enamel. J Appl Oral Sci. 2016;24:2430.

4. Ito Y, Otsuki M, Tagami J. Effect of pH conditioners on tooth bleaching. Clin Exp Dent Res. 2019;5:212-8.

5. Cavalli V, Rosa DAD, Silva DPD, Kury M, Liporoni PCS, Soares LES, et al. Effects of experimental bleaching agents on the mineral content of sound and demineralized enamels. J Appl Oral Sci. 2018;26:e20170589.

6. Vilhena KFB, Nogueira BCL, Fagundes NCF, Loretto SC, Angelica RS, Lima RR, et al. Dental enamel bleached for a prolonged and excessive time: Morphological changes. PLoS One. 2019;14:e0214948. 
7. Eskelsen E, Catelan A, Hernades NMAP, Soares LES, Cavalcanti AN, Aguiar FHB, et al.

Physicochemical changes in enamel submitted to $\mathrm{pH}$ cycling and bleaching treatment. Clin Cosmet Investig Dent. 2018;10:281-6.

8. Khoroushi M, Mazaheri H, Saneie T, Samimi P. Fracture toughness of bleached enamel: Effect of applying three different nanobiomaterials by nanoindentation test. Contemp Clin Dent. 2016;7:20915.

9. Nematianaraki S, Fekrazad R, Naghibi N, Kalhori KA, Junior AB. Effects of the bleaching procedures on enamel micro-hardness: Plasma Arc and diode laser comparison. Laser Ther. 2015;24:173-7.

10. Melo CF, Manfroi FB, Spohr AM. Microhardness and roughness of enamel bleached with $10 \%$ carbamide peroxide and brushed with different toothpastes: an in situ study. J Int Oral Health. 2014;6:18-24.

11. Favaro JC, Geha O, Guiraldo RD, Lopes MB, Aranha AMF, Berger SB. Evaluation of the effects of whitening mouth rinses combined with conventional tooth bleaching treatments. Restor Dent Endod. 2019;44:e6.

12. Khoroushi M, Shirban F, Doustfateme S, Kaveh S. Effect of three nanobiomaterials on the surface roughness of bleached enamel. Contemp Clin Dent. 2015;6:466-70.

13. Trakiniene G, Daukontiene S, Jurenas V, Svalkauskiene V, Smailiene D, Lopatiene K, et al. The effect of the teeth bleaching with $35 \%$ hydrogen peroxide on the tensile bond strength of metal brackets. Sci Rep. 2017;7:798.

14. Doméjean S, Ducamp R, Léger S, Holmgren C. Resin Infiltration of Non-Cavitated Caries Lesions: A Systematic Review. Med Princ Pract. 2015;24:216-21.

15. Prasada KL, Penta PK, Ramya KM. Spectrophotometric evaluation of white spot lesion treatment using novel resin infiltration material (ICON®). J Conserv Dent. 2018;21:531-5.

16. Wang Y, Sa Y, Liang S, Jiang T. Minimally Invasive Treatment for Esthetic Management of Severe Dental Fluorosis: A Case Report. Oper Dent. 2013;38(4):358-62.

17. Lai SCN, Tay FR, Cheung GSP, Mak YF, Carvalho RM, Wei SHY, et al. Reversal of compromised bonding in bleached enamel. J Dent Res. 2002;81:477-81.

18. Santos Gabriela Cd., Baia Juliana Cp., Ribeiro Mara Es., Lima Rafael R, Sousa E. Júnior Mário H Silva., et al. Influence of Prolonged Bleaching with 4\% Hydrogen Peroxide Containing Calcium and Different Storage Times on the Bond Strength to Enamel. J Contemp Dent Pract. 2019;20: 216-20.

19. Barghi N, Godwin JM. Reducing the Adverse Effect of Bleaching on Composite-Enamel Bond. J Esthe Dent. 1994;6(4):157-61.

20. Sung EC, Chan SM, Mito R, Caputo AA. Effect of carbamide peroxide bleaching on the shear bond strength of composite to dental bonding agent enhanced enamel. J Prosthet Dent, 82(5), 595-599.

21. Kielbassa AM, Muller J, Gernhardt CR. Closing the gap between oral hygiene and minimally invasive dentistry: a review on the resin infiltration technique of incipient (proximal) enamel lesions. Quin Int. 2009;40:663-81. 
22. Paris $\mathrm{S}$, Meyer-Lueckel $\mathrm{H}$. The potential for resin infiltration technique in dental practice. Dent Update. 2012;39:623-8.

23. Lee MH, Son JS, Kim KH, Kwon TY. Improved Resin-Zirconia Bonding by Room Temperature Hydrofluoric Acid Etching. Mater (Basel). 2015;8:850-66.

24. Theodory Tamer G, Kolker Justine L, Vargas Marcos A, Maia Rodrigo R, Dawson Deborah V. Masking and Penetration Ability of Various Sealants and ICON in Artificial Initial Caries Lesions. VitroJ Adhes Dent. 2019;21:265-72.

25. Baumann T, Bereiter R, Lussi A, Carvalho TS. The effect of different salivary calcium concentrations on the erosion protection conferred by the salivary pellicle. Sci Rep. 2017;7:12999.

26. Eggula A, VP, K S D GN, Shaik N, Fatima M. Reversal of Compromised Bond Strength of Bleached Enamel Using Cranberry Extract as an Antioxidant: an In Vitro Study. Cureus. 2019;11(11):e6188.

27. Topcu FT, Erdemir U, Ozel E, Tiryaki M, Oktay EA, Yildiz E. Influence of Bleaching Regimen and Time Elapsed on Microtensile Bond Strength of Resin Composite to Enamel. Contemp Clin Dent. 2017;8(3):451-8.

28. Arumugam MT, Nesamani R, Kittappa K, Sanjeev K, Sekar M. Effect of various antioxidants on the shear bond strength of composite resin to bleached enamel: an in vitro study. J Conserv Dent. 2014;17:22-6.

\section{Figures}

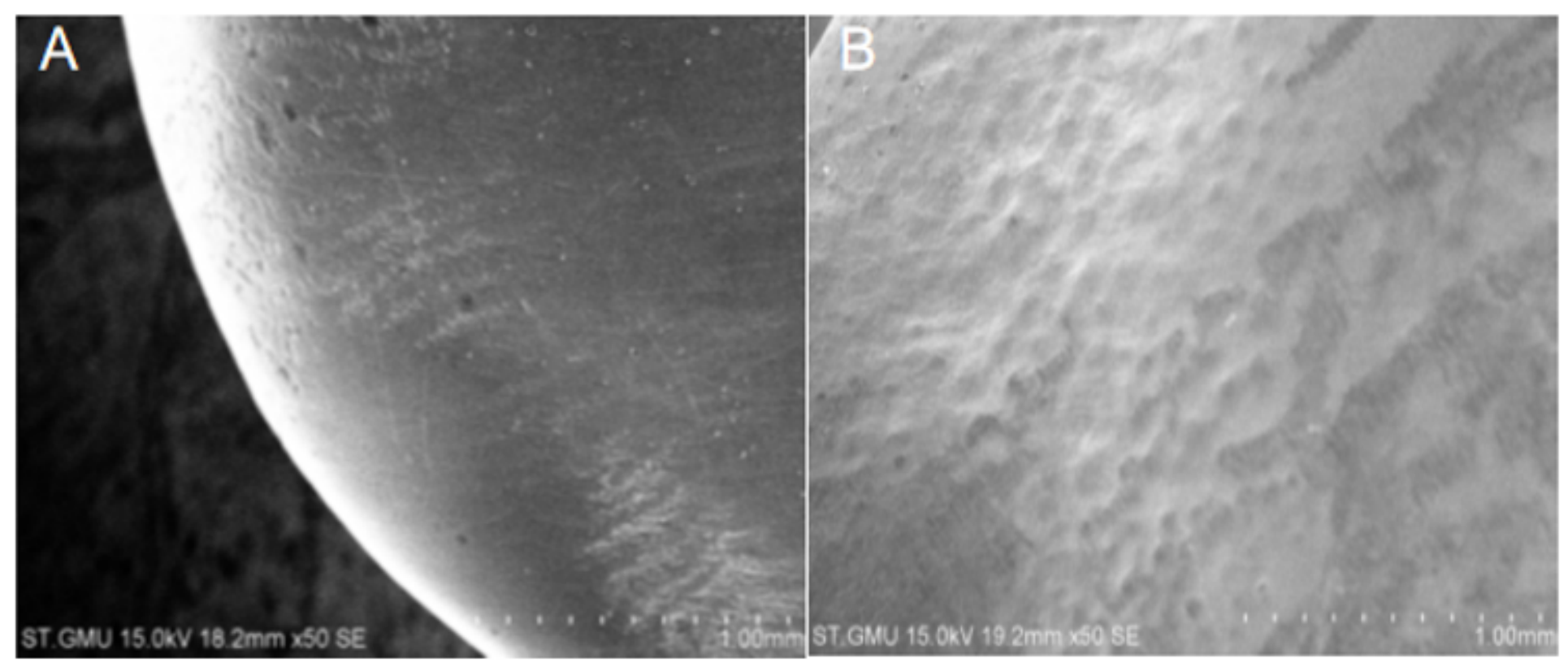

\section{Figure 1}

$A \rrbracket S E M$ view of the surface of bleached enamel (Ib 50x) B $\triangle$ SEM view of the surface of bleached and etched enamel (Ic 50x) 


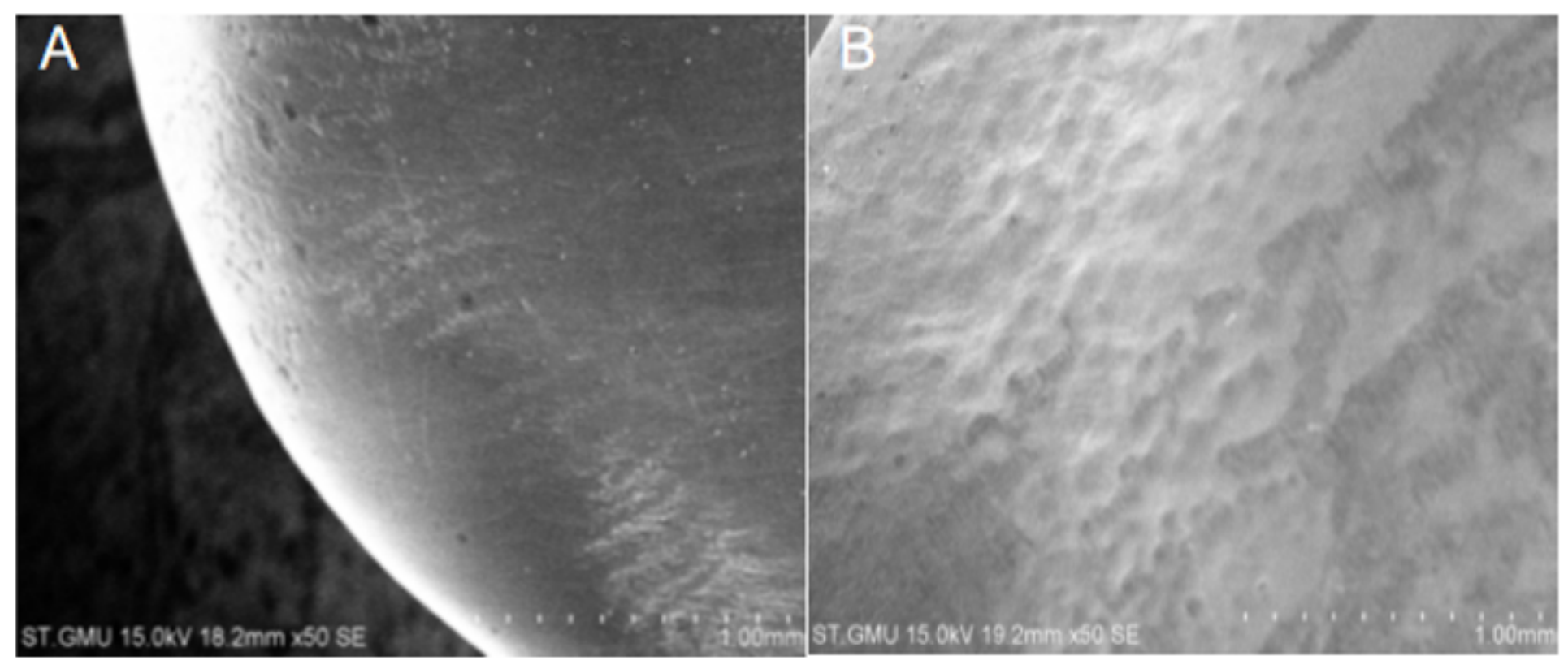

Figure 1

$A \rrbracket$ SEM view of the surface of bleached enamel (Ib 50x) B $\triangle$ SEM view of the surface of bleached and etched enamel (Ic 50x)
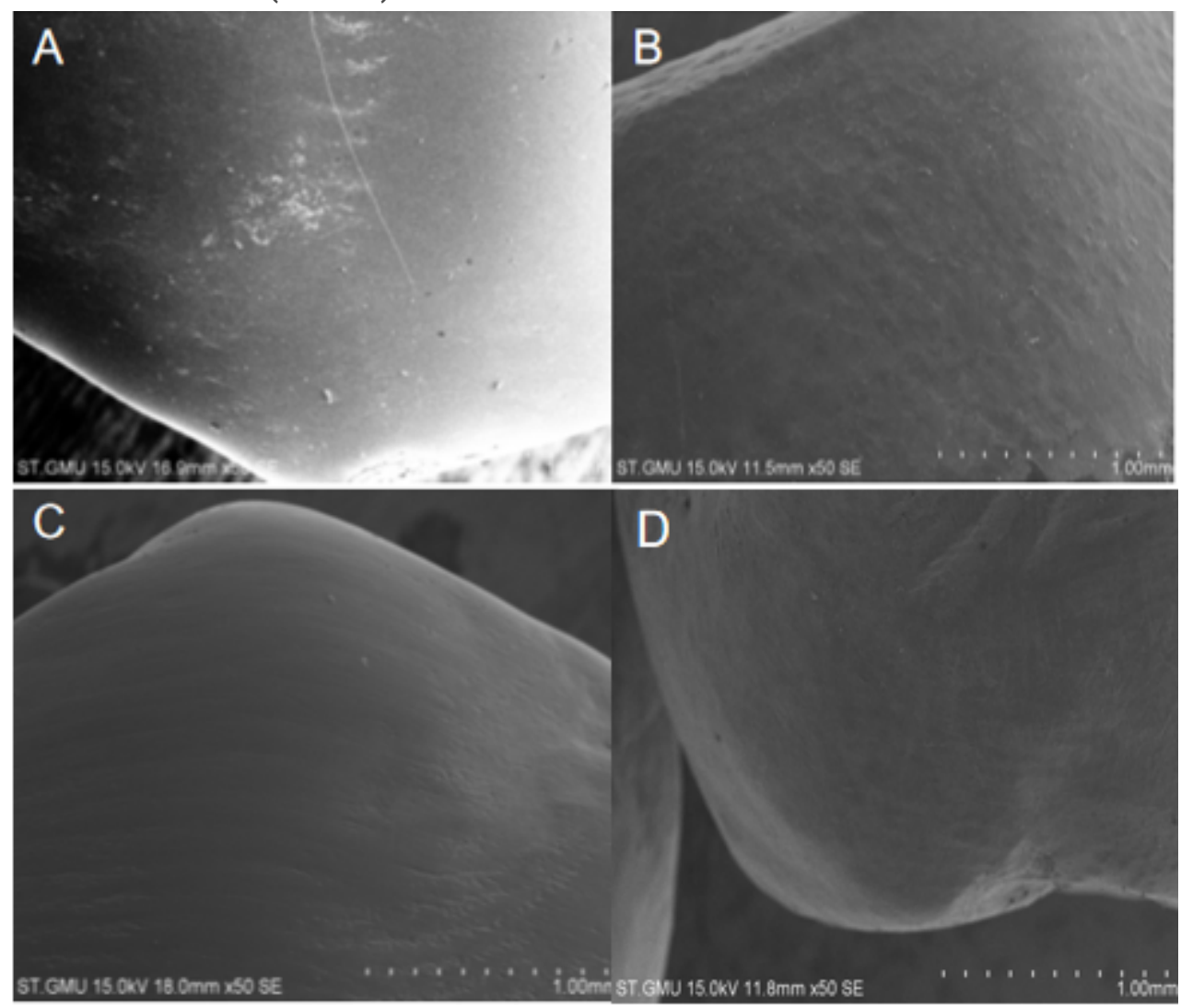

Figure 2 
$A \otimes S E M$ view of the surface of normal enamel (la 50x) B $\triangle$ SEM view of the surface of bleached enamel post resin infiltration (Id 50x) CQ SEM view of the surface of bleached and etched enamel post resin

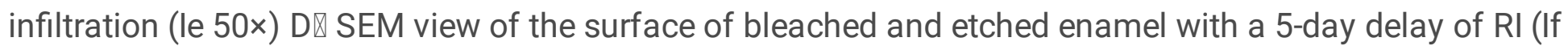
$50 \times)$

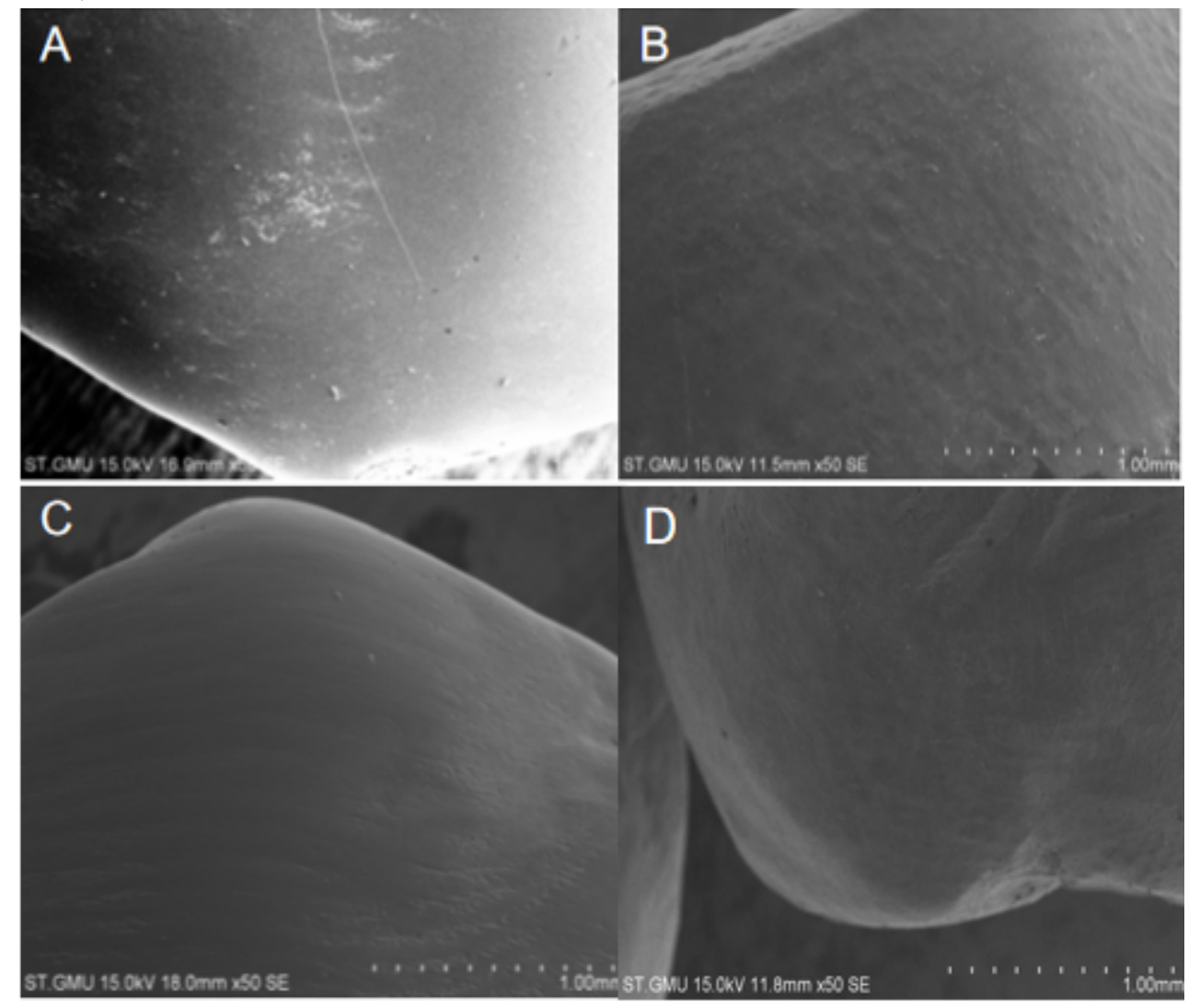

Figure 2

$A \rrbracket$ SEM view of the surface of normal enamel (la 50x) B $\triangle$ SEM view of the surface of bleached enamel post resin infiltration (Id 50x) CQ SEM view of the surface of bleached and etched enamel post resin infiltration (le 50x) D®SEM view of the surface of bleached and etched enamel with a 5-day delay of RI (If $50 \times)$

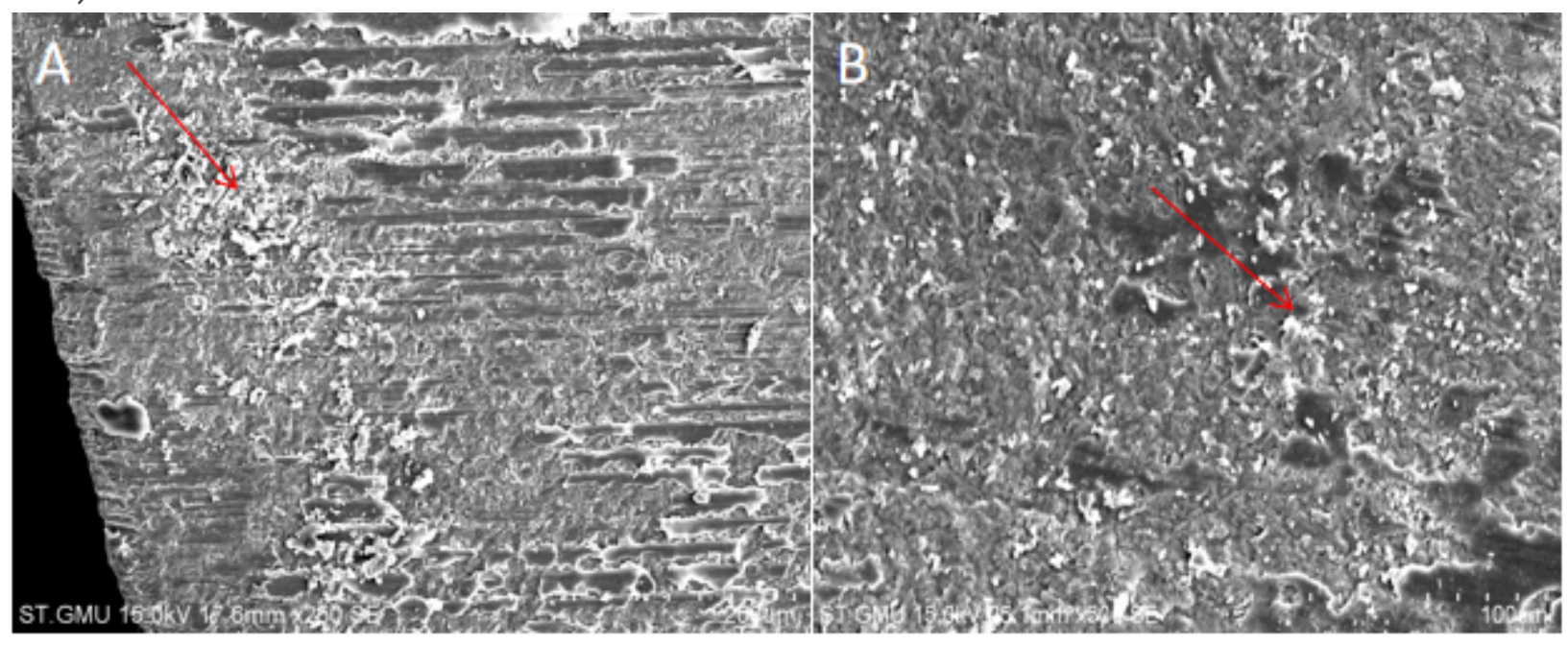

Figure 3 
$A \bigotimes S E M$ view of the penetration of resin tags in bleached enamel『lla 250x) B囚SEM view of the penetration of resin tags in bleached enamel冈lla 500x) In contrast, the deepest depths of resin penetration in Illb ranged from 391 to $540 \mu \mathrm{m}$, and the mean depth of resin infiltration was $443 \mu \mathrm{m}$ (Table 4).

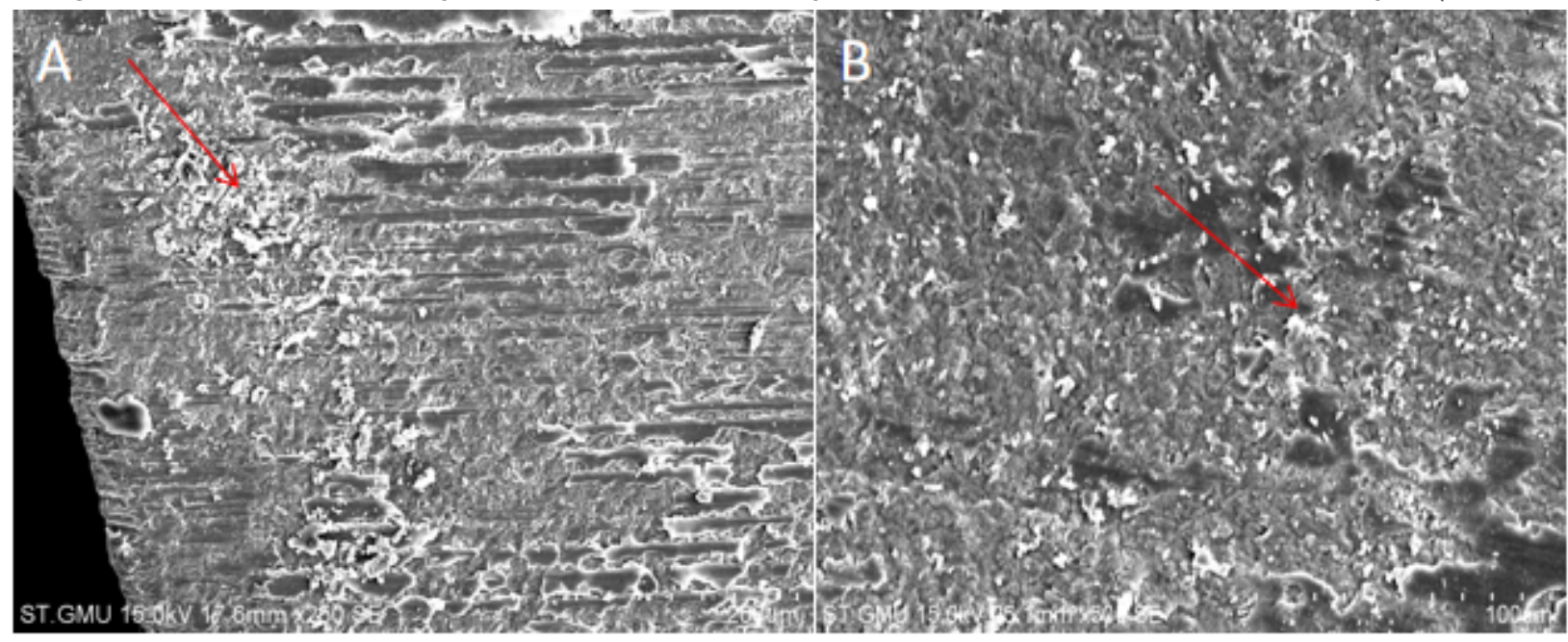

Figure 3

$A \triangle S E M$ view of the penetration of resin tags in bleached enamel『lla 250x) B $₫ S E M$ view of the penetration of resin tags in bleached enamelهlla 500x) In contrast, the deepest depths of resin penetration in Ilb ranged from 391 to $540 \mu \mathrm{m}$, and the mean depth of resin infiltration was $443 \mu \mathrm{m}$ (Table 4).

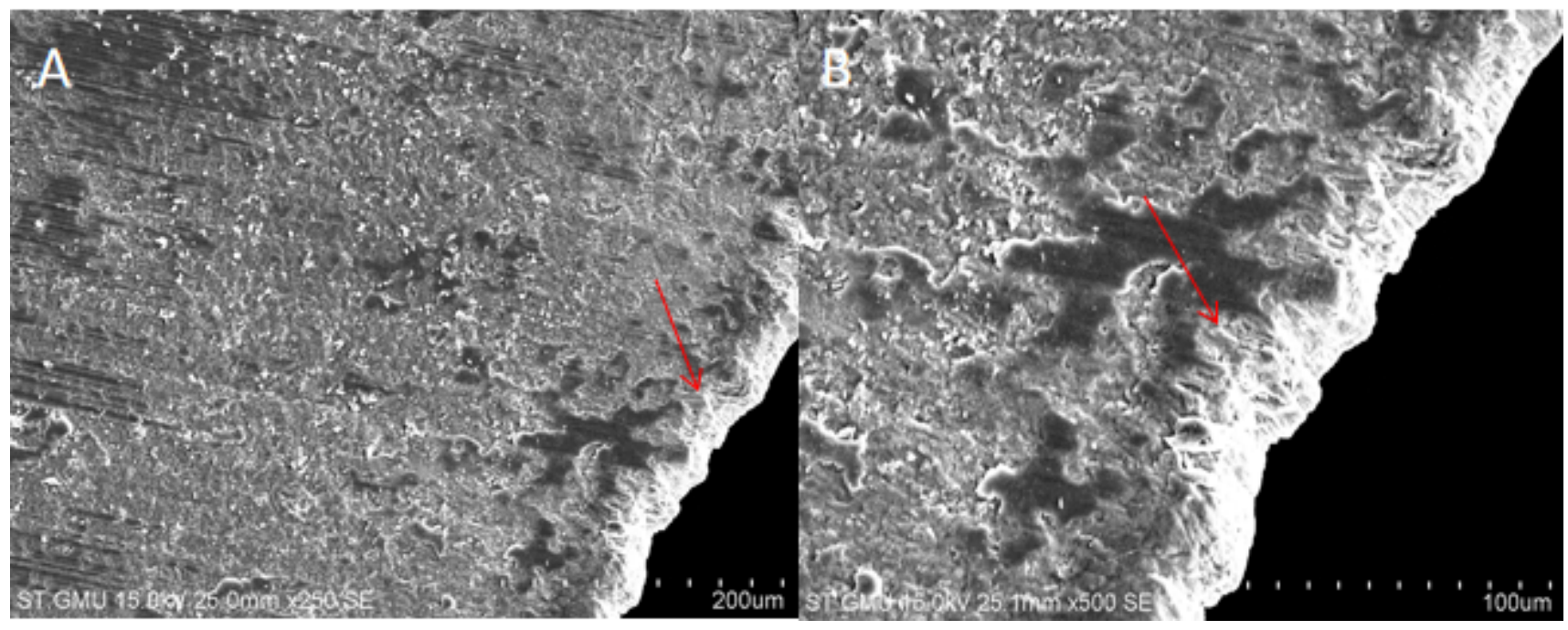

\section{Figure 4}

$A \rrbracket S E M$ view of the penetration of resin tags in bleached and etched enamel (IIb 250x) B $\triangle$ SEM view of the penetration of resin tags in bleached and etched enamel (IIb 500x) 


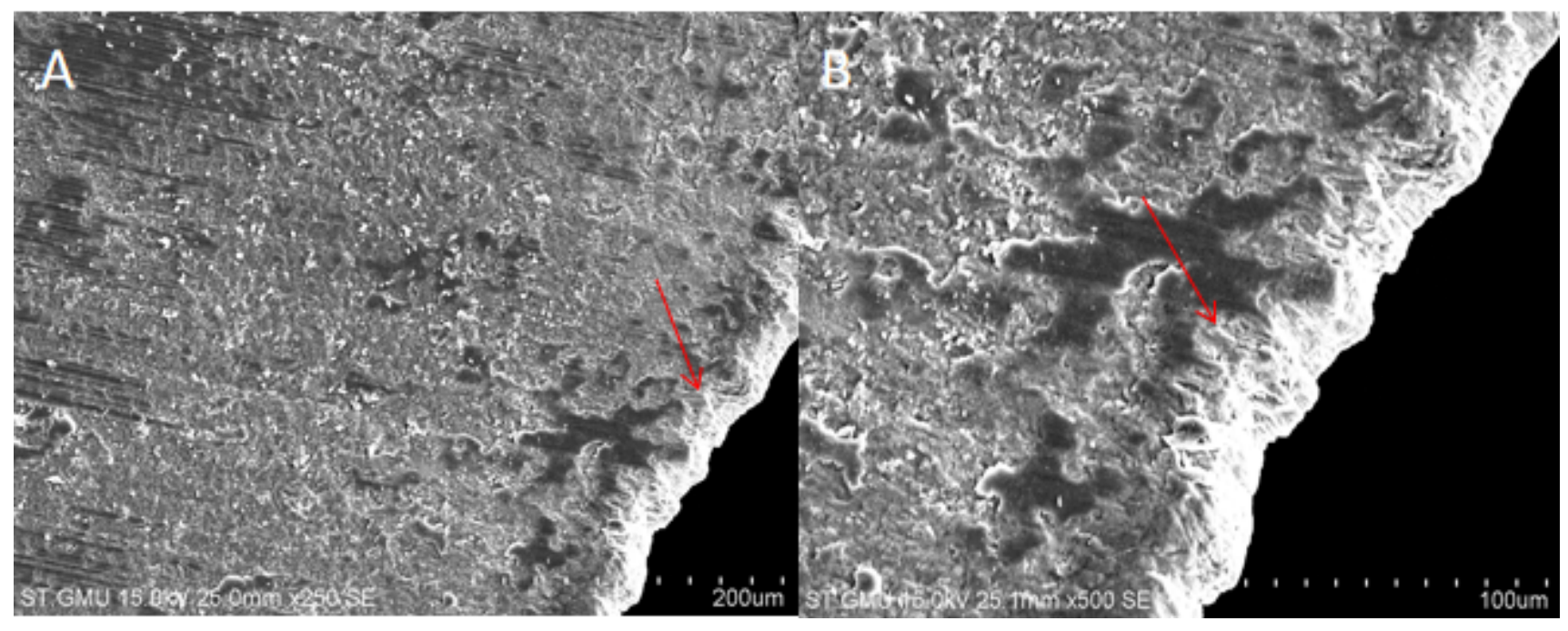

Figure 4

$A \rrbracket S E M$ view of the penetration of resin tags in bleached and etched enamel (IIb 250x) B $\triangle$ SEM view of the penetration of resin tags in bleached and etched enamel (IIb 500x)

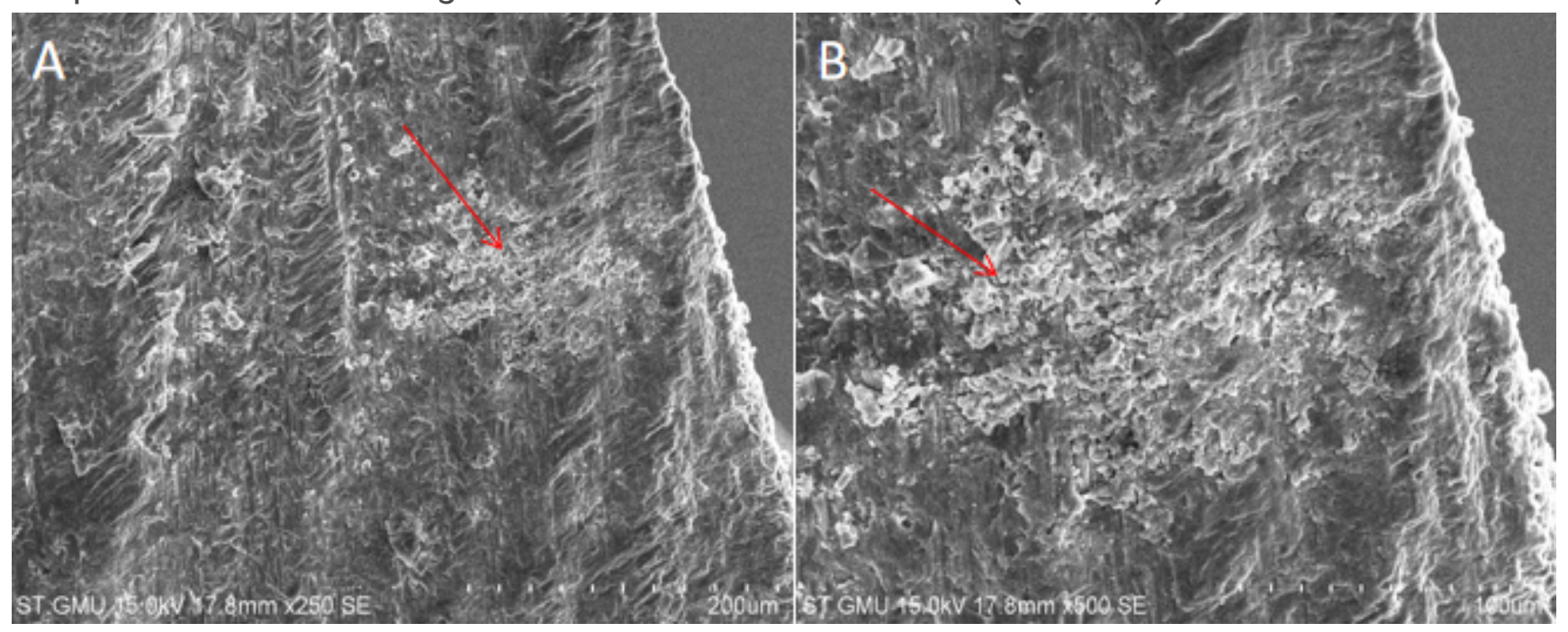

\section{Figure 5}

$A \backslash$ SEM view of the penetration of resin tags in bleached and etched enamel placed in artificial saliva for 5 days (IIc 250x) B $\triangle$ SEM view of the penetration of resin tags in bleached and etched enamel placed in artificial saliva for 5 days (Ilc500x) 


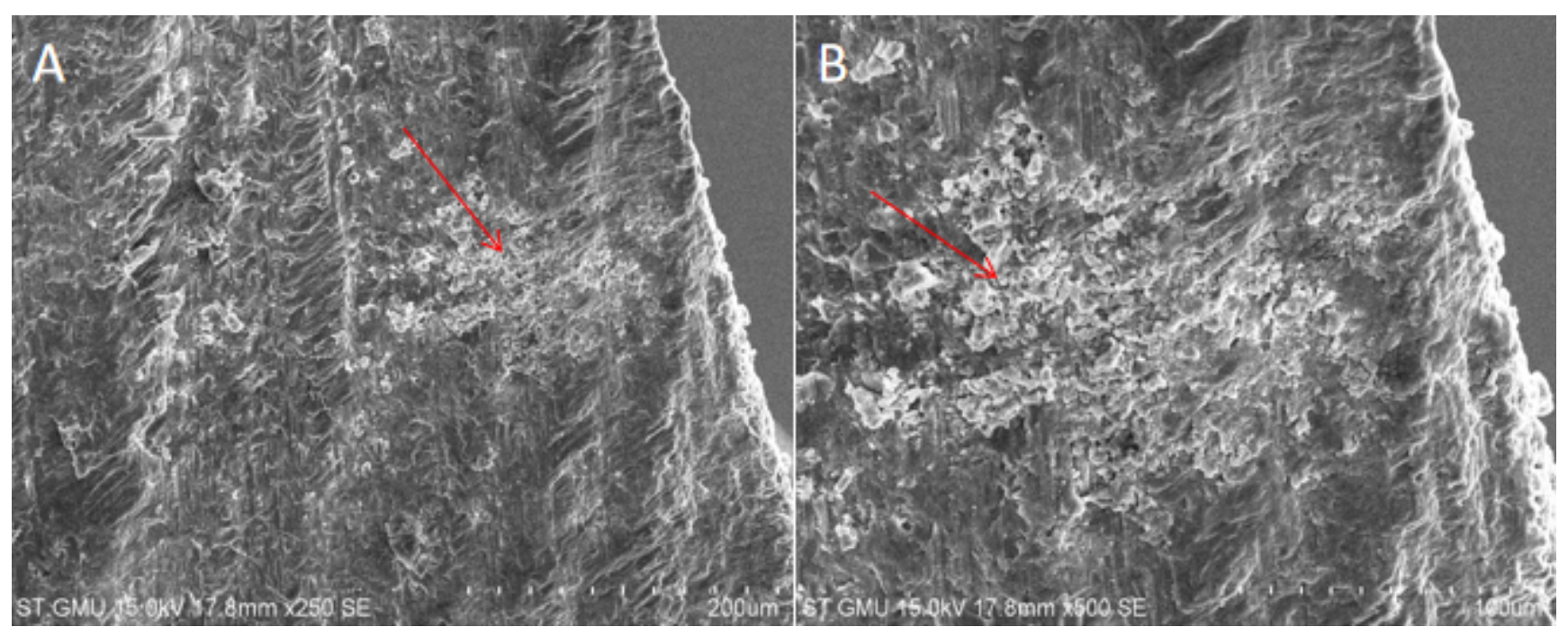

\section{Figure 5}

$A \otimes S E M$ view of the penetration of resin tags in bleached and etched enamel placed in artificial saliva for 5 days (IIC 250x) B B SEM view of the penetration of resin tags in bleached and etched enamel placed in artificial saliva for 5 days (Ilc500x) 